\title{
Stress Corrosion in Silica Optical Fibers: Review of Fatigue Testing Procedures
}

\author{
Irina Severin ${ }^{1, a)}$, Claudia Borda ${ }^{1}$, Alexandru Dumitrache-Rujinski ${ }^{1}$, \\ Mihai Caramihai ${ }^{1}$ and Rochdi El Abdi ${ }^{2}$ \\ ${ }^{1}$ University Politehnica of Bucharest, 313 Splaiul Independentei, 060042 Bucharest, Romania \\ ${ }^{2}$ University of Rennes 1, Campus Beaulieu, 35042 Rennes Cedex, France \\ a) Corresponding author: irina.severin@upb.ro
}

\begin{abstract}
The expected lifetime of optical fibers used either in telecommunication technologies or smart applications are closely related to the chemical reaction on the silica network. Due to the manufacturing processes or the handling procedures, the flaws spread on the fiber surface are inherently present. The aging mechanism is assumed to enlarge or to extend these flaws. Based on systematic experiments one may notice that water may induce a certain curing effect. Silica optical fibers have been aged in water; series of samples have been subjected to overlapped stretching or bending. Other series have been subjected to overlapped aging effect of microwaves and hot water. Finally, samples were submitted to dynamic tensile testing. The Weibull's diagram analysis shows mono or bimodal dispersions of flaws on the fiber surface, but the polymer coating appears vital for fiber lifetime. While humidity usually affects the fiber strength, the series of testing has revealed that in controlled conditions of chemical environment and controlled applied stress, fiber strength may be increased. A similar effect may be obtained by external factors such as microwaves or previous elongation, too.
\end{abstract}

\section{INTRODUCTION}

The availability of cost effective and high quality optical fibers has induced increasing applications in various areas starting with telecommunications and spreading to sensing and smart structures. Fiber reliability has remained a topical issue as long term use and fiber to the home lead to new constraints. The common expectation in terms of optical fiber life duration should be to exceed the system operation lifetime.

As known, the general structure of vitreous silica is composed by $\mathrm{SiO}_{4}$ tetrahedral. Numerous internal defects may be present accompanying chemical bonds between $\mathrm{Si}$ and $\mathrm{O}$ atoms characterizing short distance disorder. $\mathrm{OH}$ presence at the surface or inside the vitreous network, peroxide or non-bonded $O$ are generally considered intrinsic defects. In vitreous silica, $\mathrm{Si}-\mathrm{O}$ bonds fracture due to water molecules results in fracture propagation, water reaction appears dramatic for fracture behavior. Hydrolyze reaction between water and silica appears more important if an applied constraint acts, so at the fracture tips where the stress concentration is higher, water is more reactive $[1,2]$.

Surface defects geometry may be modified when applying quite low constraint, significantly lower than the failure stress [3]. In controlled conditions of time, temperature and applied constraint the microcracks tip geometry may change. In the case of low stress intensity $K_{l}$, uniform corrosion of tip geometry is observed. Contrary, at high stress intensity $K_{I}$, the stress has maxima at crack tip, favoring corrosion phenomenon to sharpen the microcrack. Between these extreme situations, a range of intermediate constraints allows a balanced tendency between curing and sharpening the fracture tips. Microcracks' propagation velocity is based on a chemical kinetics law, heat action and activation energy to fracture diminishing when applied constraint is high. The material capacity to resist fracturing when a constraint is applied is known as stress corrosion $[4,5]$.

To ensure the long-term mechanical strength of the optical fibers, a polymer coating is applied onto the fiber surface during fabrication. The fiber coating protects the cladding from any external damage, including chemical reaction in humid environment and, not lastly, ensures fatigue protection and bending insensitivity $[6,7]$. 


\section{EXPERIMENTAL PROCEDURE}

Two types of standard single mode silica optical fibers are used for testing: Alcatel 125/250 fiber and Verrillon Inc. (Boston MA) fiber. The silica cladding of $125 \mu \mathrm{m}$ in diameter is protected with two layer epoxy-acrylate polymer coating of $250 \mu \mathrm{m}$ in diameter (Fig. 1 a). The inner layer coating is soft, with a low glass transition temperature, to protect the silica surface, to inhibit the surface micro cracks and prevent water molecule to react with the sensitive glass surface. The external coating is hard, with a high glass transition temperature, to protect the fiber against external aggression. Despite the good protection against external damage, the main limitation of the epoxy-acrylate coating lies in the sponge-type behavior to humidity. That's why for specific applications, hermetic carbon coating or inorganic ones may be applied acting as an efficient barrier against corrosive reagents, mainly water, but considering significantly different costs.

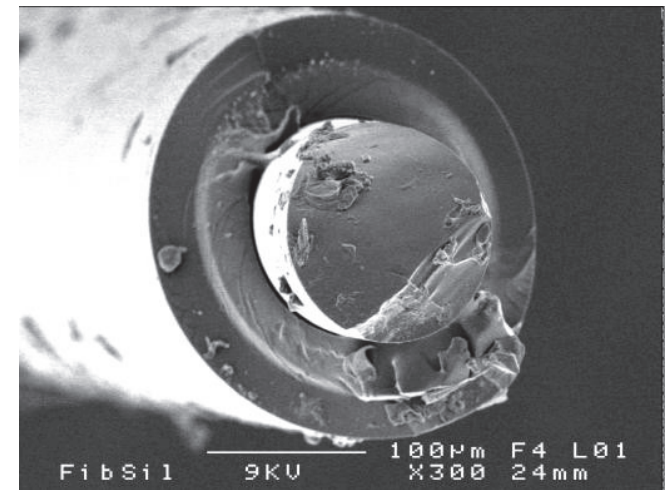

(a)

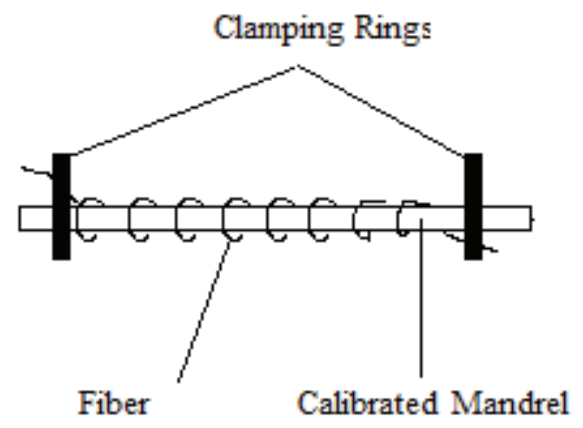

(b)

FIGURE 1. (a) SEM of tested fiber; (b) schematic representation of as-wound fiber sample on calibrated mandrel

A first series of testing consisted in aging in water with supplementary microwave, as summarized in Table 1 . The fiber sample was wound on calibrated alumina mandrel of $3.2 \mathrm{~mm}$, respectively $3.8 \mathrm{~mm}$,in diameter. The mandrel was mounted on a turning device; the strained fiber sample was wound, the ends being clamped in specially designed rings made of elastomeric-rubber (Fig. 1 b).

TABLE 1. Summaryof testing in microwave humid environment

\begin{tabular}{|c|c|c|}
\hline Alcatel commercial fiber & $3.2 \mathrm{~mm}$ mandrel & $3.8 \mathrm{~mm}$ mandrel \\
\hline $\begin{array}{l}\text { Water heated in microwave for } 2 \mathrm{~min} / \text { mandrels plunged in } \\
\text { for } 2 \mathrm{~min} \text { (notation : } 2 \text { min_without } \mathrm{uW} \text { ) }\end{array}$ & $\mathrm{x}$ & $\mathrm{x}$ \\
\hline $\begin{array}{l}\text { Mandrels plunged in water and aged in microwave for } 2 \\
\text { min (notation: } 2 \text { min_uW) }\end{array}$ & $\mathrm{x}$ & $\mathrm{x}$ \\
\hline $\begin{array}{l}\text { Mandrels plunged in water and aged in microwave for } 2 \\
\text { min, then aged for } 15 \text { min in microwave humid environment } \\
\text { (notation: } 2 \text { min uW } 15 \text { ) }\end{array}$ & $\mathrm{x}$ & $\mathrm{x}$ \\
\hline $\begin{array}{l}\text { Mandrels plunged in water and aged in microwave for } 5 \\
\text { min (notation: } 5 \text { min_uW) }\end{array}$ & $\mathrm{x}$ & \\
\hline $\begin{array}{c}\text { Mandrels plunged in water and aged in microwave for } 8 \\
\text { min (notation: } 8 \text { min } \mathrm{uW} \text { ) }\end{array}$ & $\mathrm{x}$ & \\
\hline
\end{tabular}

The applied stress on the as-wound fiber was calculated accordingly to the Malinder and Proctor relation improved by Griffioen [8,9]. For the commercial silica optical fiber (125/250) the corresponding stress was $2.743 \mathrm{GPa}$ for the calibrated mandrel of $3.2 \mathrm{~mm}$, respectively $2.31 \mathrm{GPa}$ for the calibrated mandrel of $3.8 \mathrm{~mm}$. 
Prior to aging, as-wound mandrels were soaked in cold deionized water for $5 \mathrm{~min}$. Then the overlapping aging procedure, consisting in aging in hot water and microwave humid environment, in liquid or gaseous phase, was applied in different conditions, as indicated in Table 1.

As-treated samples were dried in uncontrolled laboratory environment (temperature $18^{\circ} \mathrm{C}$, humidity $35-40 \% \mathrm{RH}$ ) for one-two days, then fibers were dynamically tensile tested in controlled environment (temperature $17-19^{\circ} \mathrm{C}$, humidity $46-52 \% \mathrm{RH}$, less than $5 \% \mathrm{RH}$ humidity variation per tested series) with different strain rates, ranging between 20 and $500 \mathrm{~mm} / \mathrm{min}$, using a tensile bench MTS (max. 1000N). The schematic tensile bench is given in Fig. 2 a.

The as-treated fiber was unwound immediately before testing. Usually, tensile 3-4 tests were possible using the length of the mandrel wound fiber. Failure stress (notation FS, MPa) was calculated considering the registered failure load.

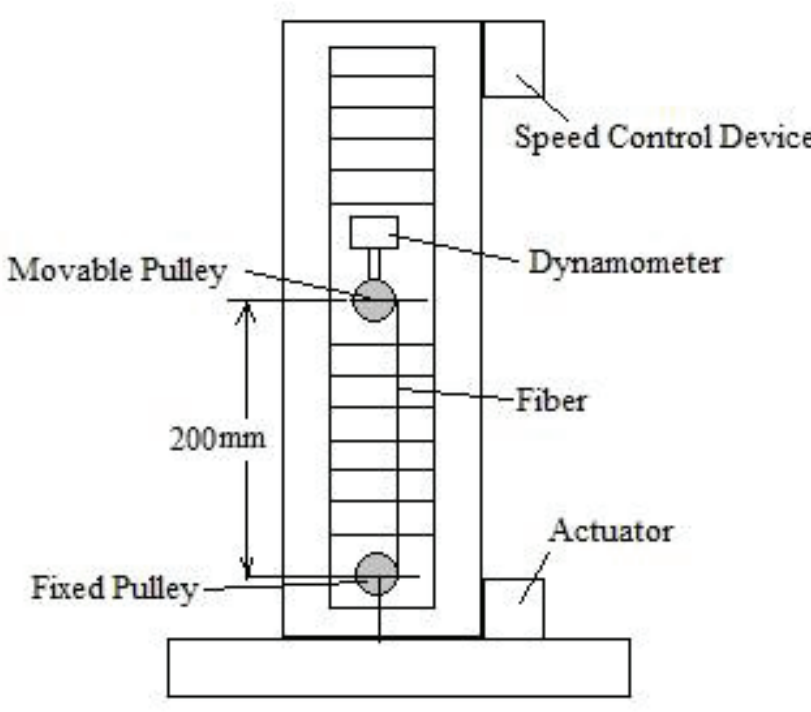

(a)

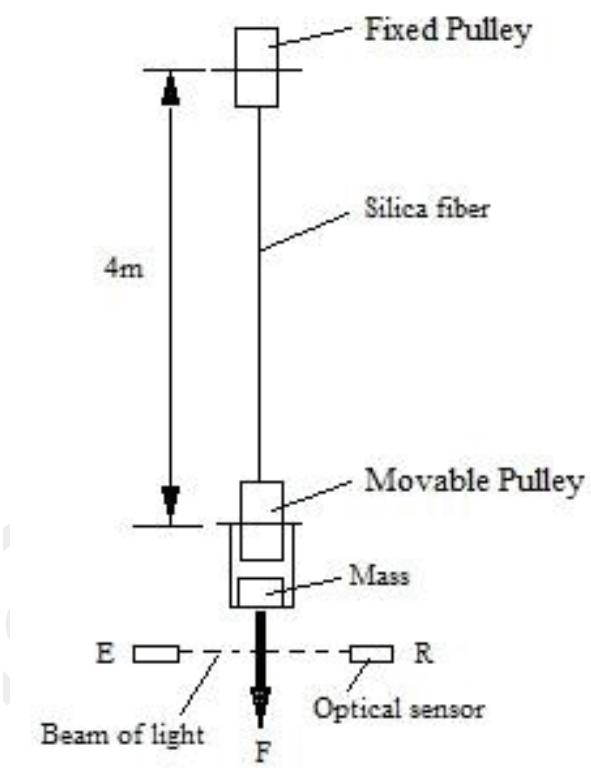

(b)

FIGURE 2. Tensile testing benches(a) Schematic description of the dynamic tensile-testing bench; (b) Schematic description of vertical static tensile-test bench: sample fiber under mass loading

A second series of testing consisted in aging in water in pre-strained conditions, using a pre-stretching device, given in Fig. 3, then vertical tensile loading with a mass of $5 \mathrm{~N}$, as seen in Fig. 2 b; finally, the as-prepared samples were dynamically tensile tested, similar to the first series, using different strain rates.

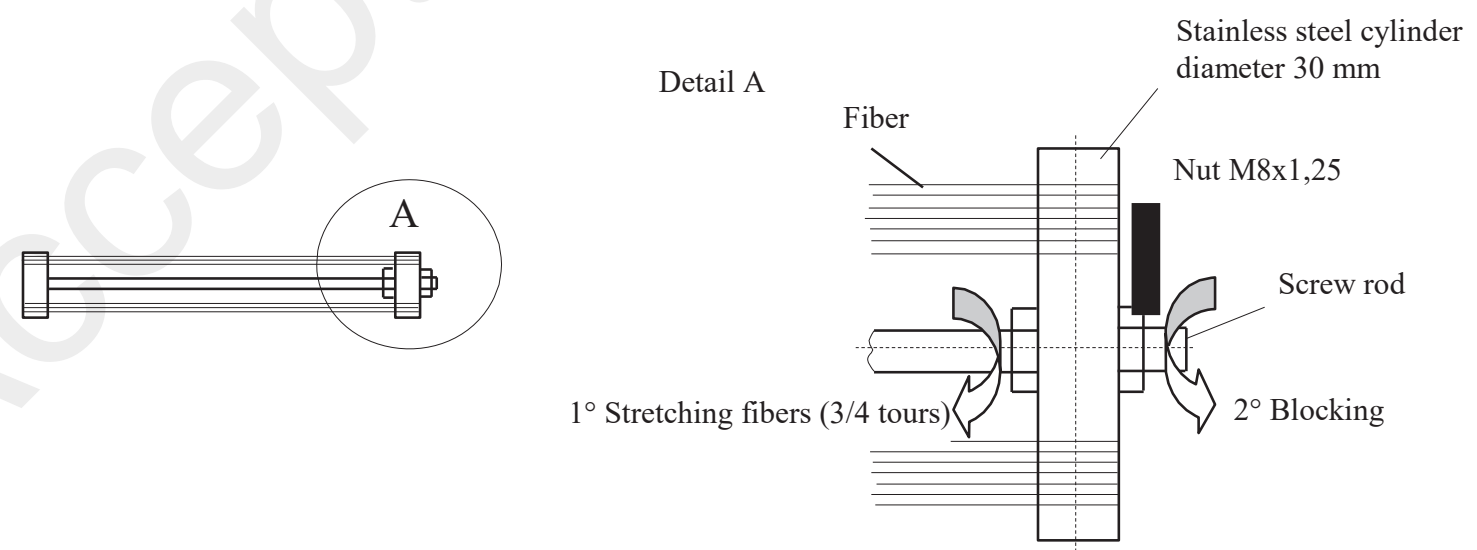

FIGURE 3. Schematic description of the pre-stretching device 
Fibers were rolled up around two cylinders of $30 \mathrm{~mm}$ in diameter, made of stainless steel. Using a strew rod, the fiber was stretched moving away the two cylinders. Two nuts were used for stretching and blocking the device, as seen in Fig. 3. In pre-strained condition ( $3 / 4$ tours correspond to $113 \mathrm{MPa}$ ), the fiber was plunged in hot deionized water at $65^{\circ} \mathrm{C}$, respectively $85^{\circ} \mathrm{C}$, for different durations ranging between 7 and 30 days.

After one-two days in laboratory, as prepared fiber sample was further submitted to static tensile loading, as seen in Fig. 2b. The fiber was rolled on the pulleys and the movable lower pulley was loaded with a suspended mass of $5 \mathrm{~N}$ for 7 days, respectively 14 days. Considering the commercial tested fiber (Verrillon 125/250), the corresponding stress was $407.3 \mathrm{MPa}$. The second series of testing conditions is summarized in Table 2.

TABLE 2. Summaryof testing in pre-stretched conditions

\begin{tabular}{cccccccc}
\hline \multirow{2}{*}{ Verrillon fiber } & \multicolumn{2}{c}{ Aging temperature, ${ }^{\circ} \mathrm{C}$} & \multicolumn{2}{c}{ Aging duration, days } & \multicolumn{2}{c}{ 5 N Loading duration, } \\
\cline { 2 - 8 } days
\end{tabular}

notation : temperature $(65,85)^{\circ} \mathrm{C}$; if pre-straining applied, $3 / 4$ tours; aging duration, $(7,14,30) \mathrm{d}$;

+ if subsequent loading applied, $5 \mathrm{~N}$; loading duration, $(7,14) \mathrm{d}$

Finally, the fiber samples were recovered and dynamically tensile tested using different strain rates. The fiber was rolled up on the pulleys covered with a powerful adhesive to avoid fiber slip. A testing length of $200 \mathrm{~mm}$ of the fiber sample was adjusted (Fig. 2 a). The results were compared to as-aged fibers in hot water without any pre-straining and further tension.

\section{RESULTS AND DISCUSSION}

The influence of the different aging procedures on the fiber mechanical strength has been evidenced using the statistical Weibull distribution that gives the relation between the logarithm function of the cumulative failure probability $\boldsymbol{F}$ related to the logarithm of the fracture stress $\boldsymbol{F S}$ [10]. Interpolating the testing results, the linear distribution slope allows to evaluate the flaws size dispersion. If different slopes are noticed, different defect populations are present. Usually, at low strain rates bi or multi modal Weibull distribution may be noticed, meaning that both extrinsic and intrinsic microcracks characterize the fiber failure. At high strain rates, usually a mono-modal distribution is expected, with a high slope, meaning that failure is mainly due to a single defect population, the intrinsic microcracks [11].

The first series of testing has analyzed the overlapping effect of, on one hand, the tensile and compressive stresses applied as-winding the fiber on calibrated mandrel and, on the other hand, the aging in hot water and microwave humid environment in liquid and gaseous phase. The tensile tested results for the strain rates of $20 \mathrm{~mm} / \mathrm{min}, 100$ $\mathrm{mm} / \mathrm{min}, 200 \mathrm{~mm} / \mathrm{min}$, respectively $500 \mathrm{~mm} / \mathrm{min}$ are given in Fig. 4.

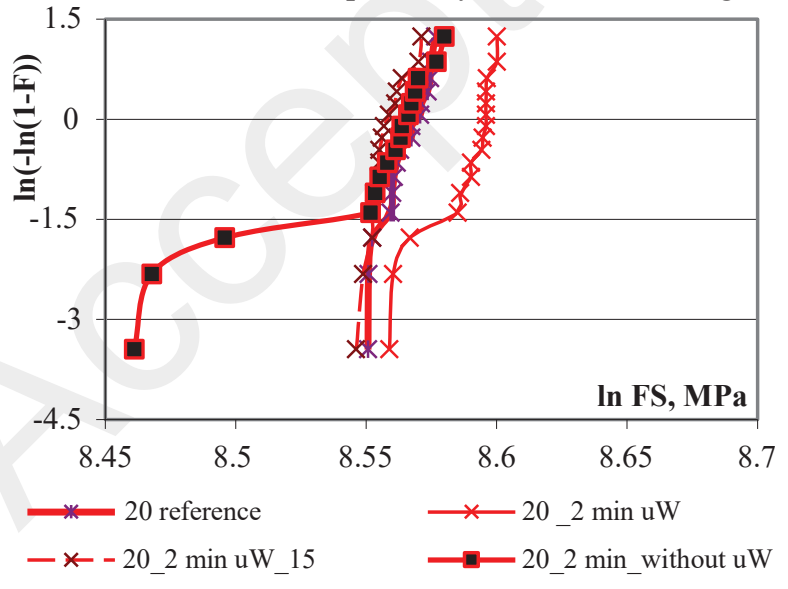

(a)

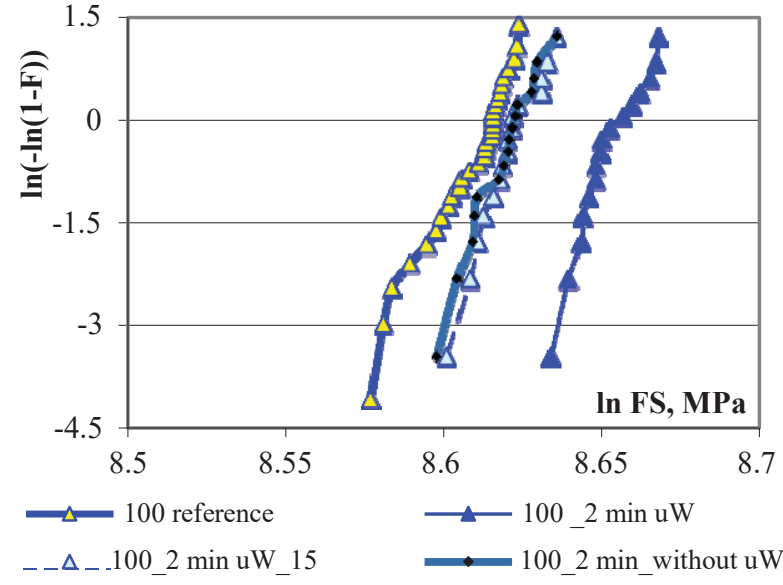

(b) 


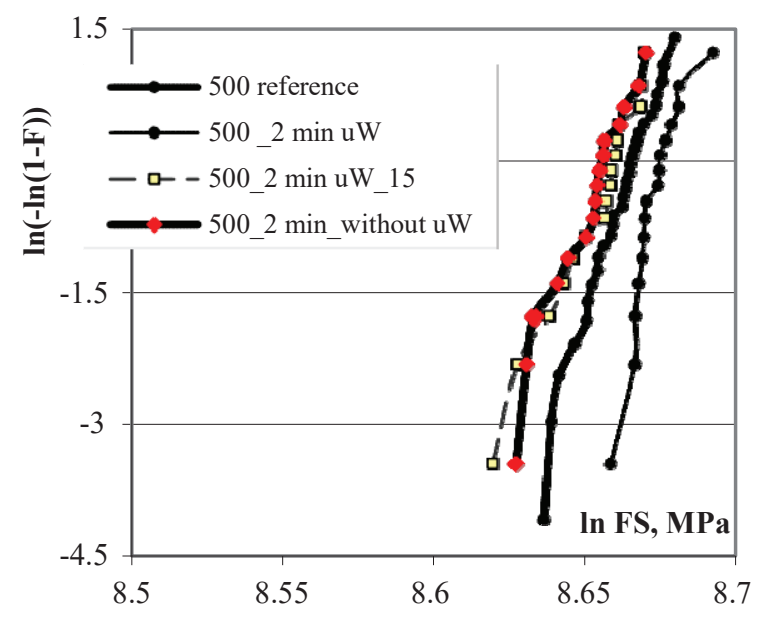

(c)

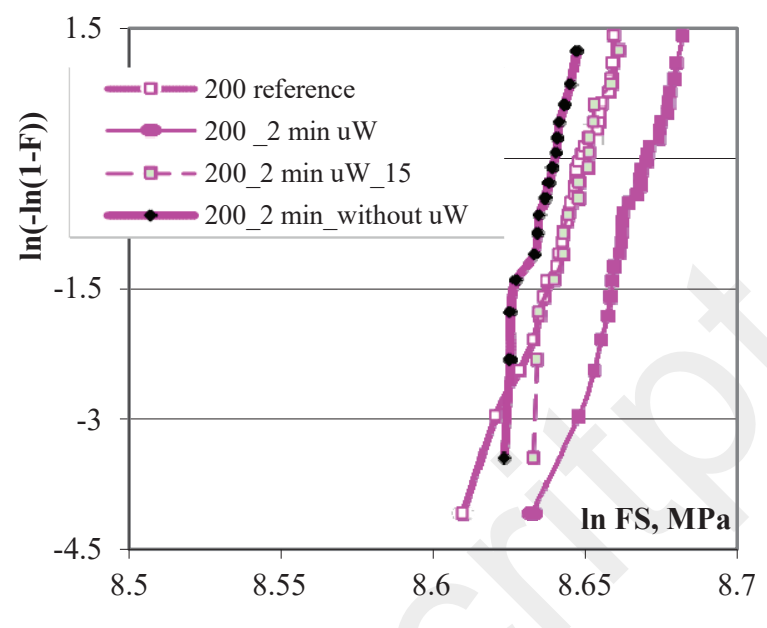

(d)

FIGURE 4. Weibull plots of as-aged fibers in microwave humid environment at different strain rates, indicated in the legend

(a) $20 \mathrm{~mm} / \mathrm{min}$, (b) $100 \mathrm{~mm} / \mathrm{min}$, (c) $200 \mathrm{~mm} / \mathrm{min}$ and (d) $500 \mathrm{~mm} / \mathrm{min}$

As seen in Fig. 4, a coherent distribution is noticed for the reference fiber; at all strain rates $(20,100,200$ and 500 $\mathrm{mm} / \mathrm{min}$ ) a mono-modal dispersion with high slope indicates mainly that intrinsic microcracks are responsible for the failure mode. Dust in fiber drawing tower or foreign particles in the coating material may be the origin of these microflaws.

For all strain rates, overlapping aging in hot water for short duration $(2 \mathrm{~min})$ with the bending effect of winding the fiber has affected the failure stress that slightly decreased. An exception was noticed for the strain rate of 100 $\mathrm{mm} / \mathrm{min}$, but the benefit appeared slight, too. For low strain rate $(20 \mathrm{~mm} / \mathrm{min})$ a change of the mono-modal dispersion towards a bi-modal one was obtained, meaning that for low strain rate the aged fiber appeared more sensitive to the externally induces defects such as due to handling.

A significant reported result appeared for overlapping bending with aging in microwave in humid environment in liquid phase. For all strain rates, an increase of the failure stress was reported in the case of the as-wound fibers aged in water in microwave. The two step treatment that prolonged exposure to microwave in humid gaseous environment led to nearly similar results to aging in water without overlapped microwave energy.

In order to compare the treatment parameters influence, Weibull plots for the strain rate of $200 \mathrm{~mm} / \mathrm{min}$ are represented in Fig. 5.

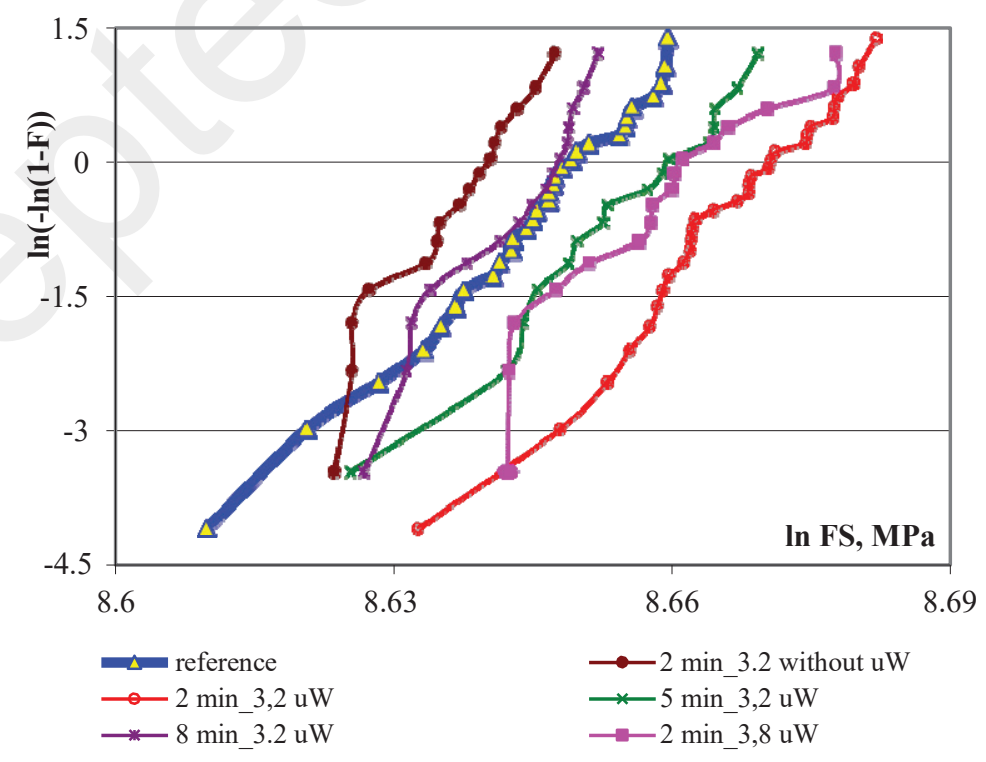

FIGURE 5 Fiber behavior in different aging conditions in microwave humid environment at the strain rate of $200 \mathrm{~mm} / \mathrm{min}$ 
One may notice that as compared to the reference, pre-straining the fiber (as-wound on mandrel) and overlapping microwaves to aging had a benefit effect on the failure stress. Prolonging the microwave treatment duration affected the stress to decrease below the reference value. For the optimal of 2 minutes microwave treatment, the higher bending stress appeared better, thus winding the fiber on the mandrel of higher diameter $(3.8 \mathrm{~mm})$ was less effective.

The second series of experiments has allowed to report a similar effect of aging in controlled conditions in terms of pre-straining and aging parameters. In certain aging conditions, one may report the failure stress improvement, based on the Weibull plots, as seen in Fig. 6...9. Dynamic tensile testing was implemented for different strain rates of $50 \mathrm{~mm} / \mathrm{min}$ (Fig. 6), $150 \mathrm{~mm} / \mathrm{min}$ (Fig. 7), $300 \mathrm{~mm} / \mathrm{min}$ (Fig. 8), respectively $500 \mathrm{~mm} / \mathrm{min}$ (Fig. 9).

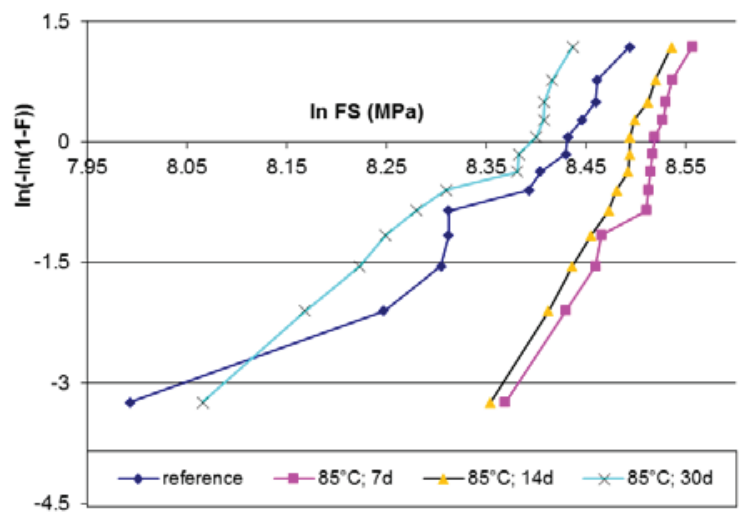

(a)

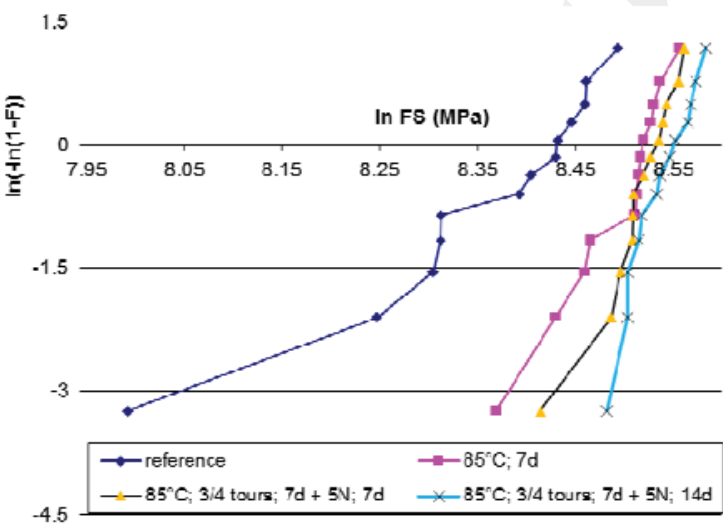

(b)

FIGURE 6.Weibull plots of as-aged fibers, tested at $50 \mathrm{~mm} / \mathrm{min}$ strain rate: (a) comparison of aging duration,

(b) influence of pre-stretching and tension relaxation under load

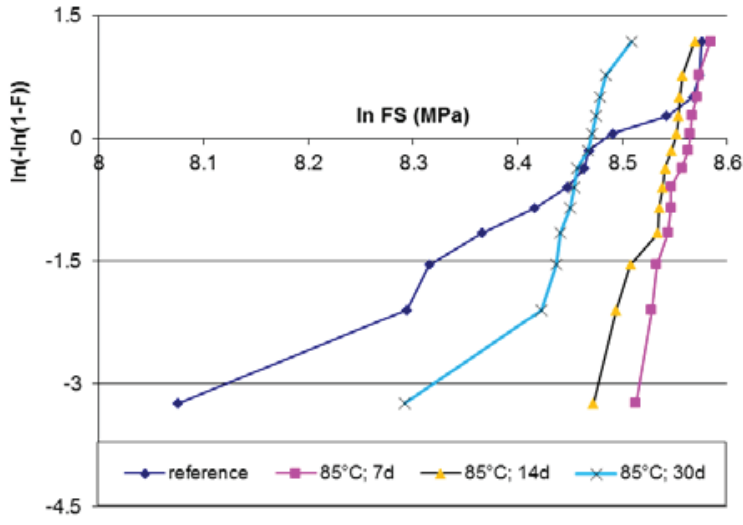

(a)

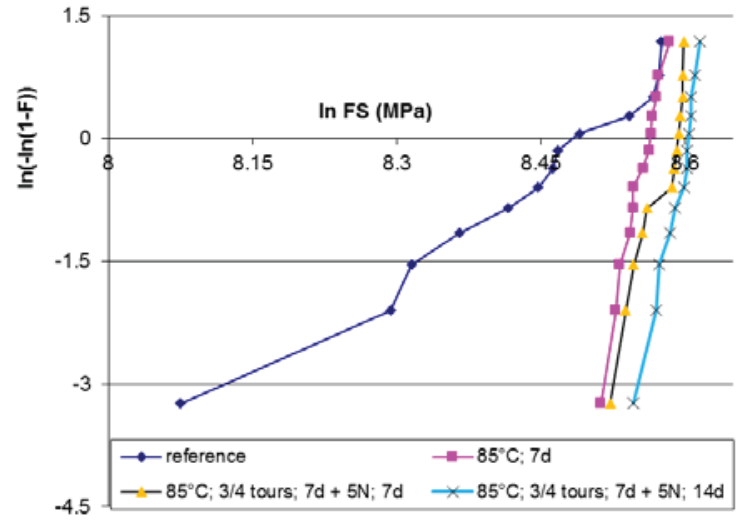

(b)

FIGURE 7.Weibull plots of as-aged fibers, tested at $150 \mathrm{~mm} / \mathrm{min}$ strain rate: (a) comparison of aging duration,

(b) influence of pre-stretching and tension relaxation under load

The second series of experiments was implemented on a different fiber, Verrillon Inc. (125/250). The reference fiber presented moreover a bi or multi-modal distribution for all strain rates, with a low slope parameter, exhibiting generally extrinsic defects responsible failure mode.

Comparing the aging parameters effect, for all strain rates $(50 \mathrm{~mm} / \mathrm{min}, 150 \mathrm{~mm} / \mathrm{min}$ and $300 \mathrm{~mm} / \mathrm{min}$, but less effective for $500 \mathrm{~mm} / \mathrm{min}$ ) aging in hot water for 7 days has allowed to report an increased failure stress and the change failure mode towards a mono-modal one. Prolonging the aging duration for 14, respectively 30 days, a decrease of the failure stress was obtained, the optimal duration in this series of testing being reported to 7 days. The mono-modal dispersion seemed to be remaining for the 14 days aging duration, changing to the bimodal one for a prolonged aging 
treatment (30 days). The result may be explained based on the stress corrosion phenomenon, the defects being cured subsequent to aging in controlled conditions.

The sharp crack tip of non-aged silica fibers may be cured as a fine deposit of hydrated silica rounded microcracks' bottom, decreasing stress intensity factor and fracture extension rate.

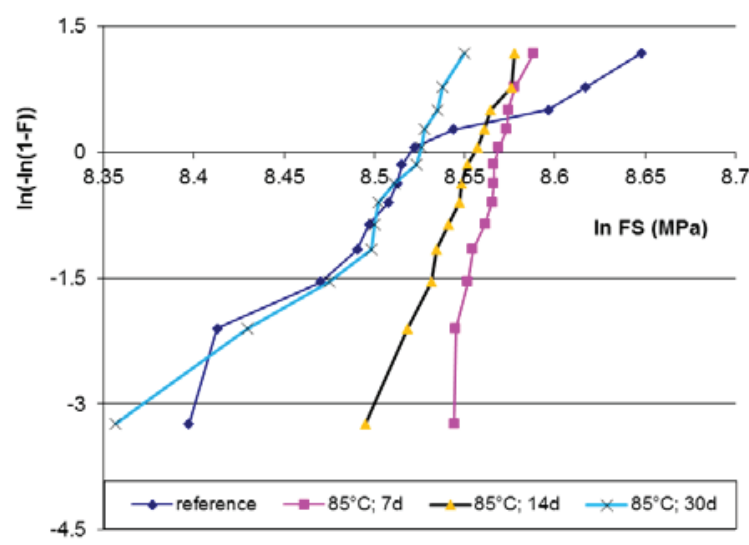

(a)

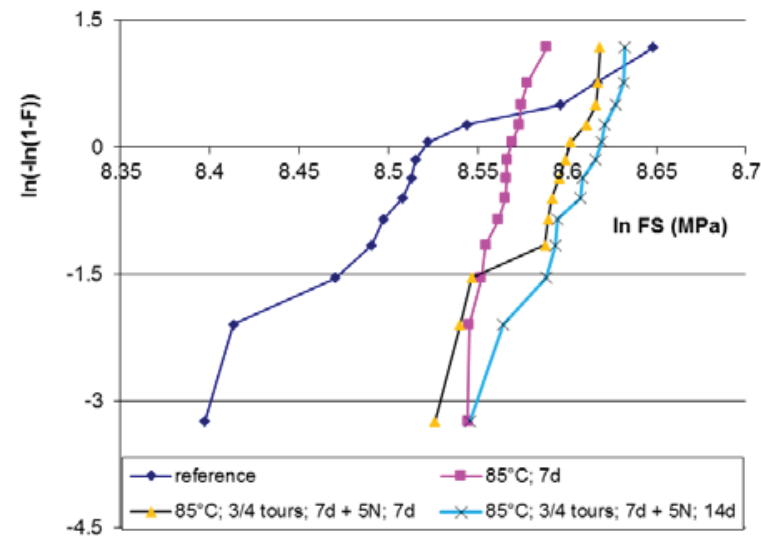

(b)

FIGURE 8. Weibull plots of as-aged fibers, tested at $300 \mathrm{~mm} / \mathrm{min}$ strain rate: (a) comparison of aging duration,

(b) influence of pre-stretching and tension relaxation under load

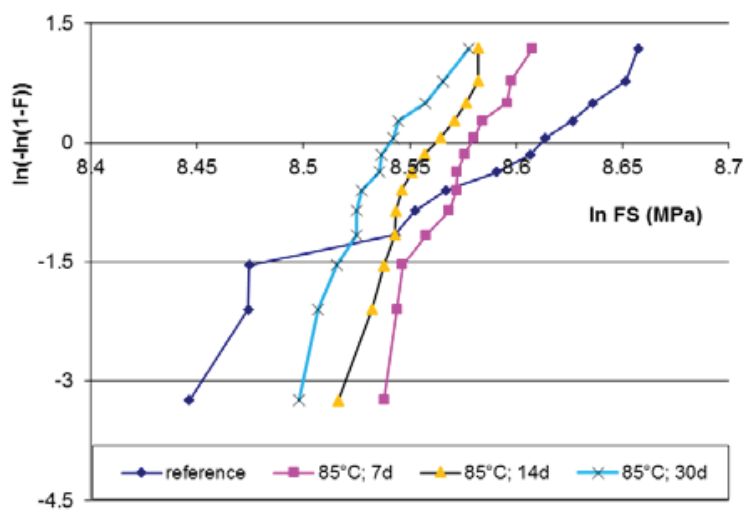

(a)

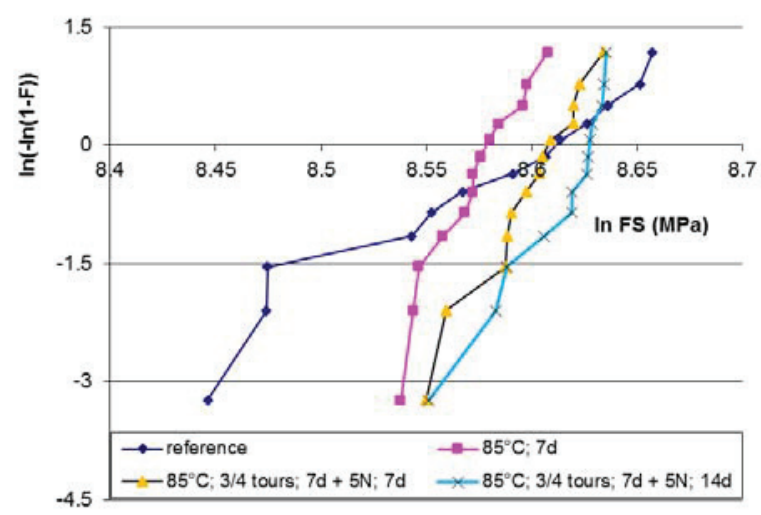

(b)

FIGURE 9. Weibull plots of as-aged fibers, tested at $500 \mathrm{~mm} / \mathrm{min}$ strain rate: (a) comparison of aging duration,

(b) influence of pre-stretching and tension relaxation under load

Finally, considering the overlapped pre-stretching effect to aging in hot water, followed by tension relaxation under load for 7, respectively 14 days, one may notice the benefit for the failure behavior. The failure stress has increased for all strain rates, but for higher strain rates a bi or multi- modal dispersion may be noticed.

Similar testing were performed for longer duration of tension relaxation under load, but the benefit has been lost. Comparing the two series of testing, it appears interesting to note that pre-straining the fiber either through bending or stretching in tension in controlled conditions and then aging in hot water for a controlled duration overlapping a supplementary energy (microwave in humid environment) or complementing with relaxation under load allowed improvement of failure behavior of the optical fiber. 


\section{CONCLUSION}

The polymer coating appears vital for silica optical fiber lifetime [12]. Certain progress may be registered replacing the commercial epoxy-acrylate polymer [13], but being less expensive and high quality it still finds extensive use for various applications [14].

The systematic implemented testing allowed summarizing that fiber strength evolution under controlled applied stress and accelerated aging due to supplementary microwave energy revealed a certain improvement. Normally, fiber strength decrease is expected due to water chemical action, but applied stress and microwave energy have acted in an opposite manner, microwave in humid environment (in liquid phase) acting as a relaxation factor. The effect may be explained through the fiber-polymer interface structural relaxation. At the cladding surface, a hydrated silica layer is likely to be formed, inhibiting a part of the microflaws and enhancing the fiber failure behavior.

A similar result may be reported when comparing fiber strength evolution in hot water with overlapped prestraining and loading under stress. Pre-strained and aged (in hot water) fibers, then loaded under controlled stress, have presented a certain increased failure stress that may be explained through the opposite effect of aging and static fatigue; the microflaws become rounded thus inhibiting, to a certain extent, surface defects propagation.

The significant result of this systematic experimental campaign lies in curing surface defects by aging in controlled conditions of temperature, aging duration and applied stress.

\section{ACKNOWLEDGMENTS}

The Verrillon fiber was generously offered for testing by Verrillon Inc. (Boston, MA); the authors are grateful for the materials and technical assistance. Reported testing were performed in LARMAUR Laboratory, Campus of Beaulieu, University of Rennes 1, France, as part of the bilateral cooperation.

\section{REFERENCES}

1. M. Poulain, Fundamental of optical fibers (private communication)

2. J. L. Mrotek, M. J. Matthewson, C. R. Kurkjian, "Diffusion of moisture through optical fiber coatings", J. Lightwave Technol. 19 (7), 988-993 (2001)

3. R. J. Charles and W. B. Hillig, "The kinetics of glass failure by stress corrosion", Symposium sur la resistance du verre et les moyen de l'ameliorer, Charleroi: Union Scientifique Continentale du Verre, (1962), pp. 511-527

4. N. Evanno, "Contribution a l'etude de la fiabilite mecanique des fibres optiques: Application a l'optimisation des modeles de duree de vie sous environnement severe“, Ph.D. thesis, University of Rennes 1, 1999

5. N. Gougeon, "Rupture et vieillissement des fibres optiques", Ph.D. thesis, University of Rennes 1, 2003

6. I. Severin, M. Poulain, R. El Abdi, J. Optoelectronics \& Adv. Mat., Vol. 9, nr. 7, 2110-2015 (2007)

7. I. Severin, R. El Abdi, M. Poulain, Optics \& Laser Tech., vol 39, no 2, p. 435-441 (2007)

8. W. Griffioen, "Optical fiber reliability", Ph.D. thesis, Royal PTT, The Netherlands NV, PTT Research, Leidschendam, 1994

9. I. Severin, R. El Abdi, M. Poulain, "Phenomena associated to silica optical fibers", in Photonic Applications in Devices and Communication Systems, Proc. Of SPIE vol 5970, 597001, (2005), edited by P. Mascher et al.

10. B. Bergman, J. Mater. Sci. 5, p. 611-614 (1986)

11. R. El Abdi, A. Rujinski, C. Borda, I. Severin, M. Poulain, Optics \& Lasers in Eng. 46, p. 222-229 (2008)

12. Y.Wu, H. Yu, S. Chen, J. Luo, Journal of Non-Crystalline Solids 383, p. 81-85 (2014)

13. A. K. Dikshit, Int. J. Plastics Technol., vol. 20, nr. 2, 1p. 401-423 (2016)

14. Q. Zao, Y. Qu, Y. J. Wang, F. Li, Applied Optics 52(11), p. 2478-83 (2013) 